DESIGN E INOVAÇÃO SOCIAL Processos Colaborativos, Codesign e Identidade 


\section{SOBRE OS AUTORES}

Aron Krause Litvin | aron@estudionomade.com.br

Lattes: http://lattes.cnpq.br/0176782732169768

Mestre em Design Estratégico, é também cofundador do laboratório TransLAB, diretor na consultoria de inovação social Estúdio Nômade e professor de Empreendedorismo e Inovação no PPG - UniRitter. Sua produção acadêmica desenvolve o conceito da colaboração no âmbito dos laboratórios de inovação social.

Carlo Franzato | cfranzato@unisinos.br

Lattes: http://lattes.cnpq.br/4881062407464026

Carlo Franzato é designer e doutor em Design pelo Politecnico di Milano. É decano da Escola da Indústria Criativa da Universidade do Vale do Rio dos Sinos (Unisinos). Nessa escola, é professor dos cursos de graduação, especialização, mestrado e doutorado em Design, e supervisor de pós-doutorado. Na perspectiva do design estratégico, sua pesquisa tem como tema central as redes de projeto que se constituem com a abertura do processo de design para as inúmeras colaborações projetuais que se estabelecem entre designers e outros profissionais, empresas e organizações, usuários e cidadãos. É membro do grupo de pesquisa Design estratégico: inovação cultural e social, das redes internacionais Latin Network for the Development of Design Processes e Design for Social Innovation and Sustainability. Integra o SeedingLAB, laboratório para a prática de design, voltado à inovação social e à sustentabilidade. 


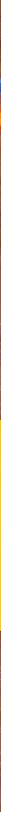

\title{
Os efeitos do codesign no contexto emergente das Casas Colaborativas
}

\section{The effects of codesign in the emerging context of Collaborative Houses}

\author{
Aron Krause Litvin, Carlo Franzato
}

\section{Resumo}

0 presente estudo apresenta uma discussão a respeito da evidência do projeto colaborativo no âmbito das Casas Colaborativas. Os movimentos processuais que acontecem nesses espaços são dinâmicos e articulam uma diversidade de sujeitos. Nesse sentido, o codesign apresenta uma abordagem que está em relação com os escopos das Casas Colaborativas. A intersubjetivação aponta para entendimentos que ampliam os efeitos dos projetos colaborativos. Como resultados, têm-se a elaboração da conceituação de uma Casa Colaborativa, a adesão de Casas ao Projeto Lixo Zero e a construção de um site das Casas Colaborativas.

Palavras-chave: Codesign; Design Estratégico; Intersubjetivação; Inovação Social; Casas Colaborativas.

\section{Abstract}

This study presents a discussion about the evidence of the collaborative project within the Collaborative Houses. The procedural movements that take place in these spaces are dynamic and articulate a diversity of people. In this sense, the codesign presents an approach that is related to the Collaborative Houses scopes. Intersubjectivation points to understandings that amplify the effects of collaborative projects. As results, the elaboration of the concept of a Collaborative House, the adhesion of some houses to the Zero Waste Project and the construction of a Collaborative Houses website.

Keywords: Codesign; Strategic Design; Intersubjectivation; Social Innovation; Collaborative Houses. 


\section{INTRODUÇÃO}

A perspectiva ecossistêmica nos permite compreender que o processo de inovação social é hoje desenvolvido em ecossistemas criativos. Um "ecossistema criativo é um tipo de ecossistema cultural caracterizado pelo desenvolvimento de processos criativos que resultam em dispositivos sociotécnicos possivelmente originais e inovadores" (FRANZATO et al, 2015, p. 171). Entende-se por inovação social "as mudanças no modo como indivíduos ou comunidades agem para resolver seus problemas ou criar novas oportunidades" (MANZINI, 2008, p. 61). Nesse tipo de ecossistema encontram-se iniciativas criativas capazes de transformações nas realidades em que atuam. Essas "iniciativas criativas" (locução que deixamos oportunamente ainda genérica) abordam problemas sociais complexos, procurando a participação de diferentes sujeitos, sua colaboração, o compartilhamento de visões alternativas para o futuro. Os desafios a serem enfrentados são inúmeros e as soluções que podem ser elaboradas também.

A possibilidade de encontrar soluções para que ocorram tais transformações vincula-se à prática projetual e especialmente ao design estratégico. A complexidade dos ecossistemas criativos, de fato, demanda, de um lado, competências criativas, para vislumbrar possibilidades de inovação social, e de outro, competências estratégicas, para conseguir enfrentar a complexidade ecossistêmica.

Para Mauri (1996), a palavra estratégia promove um efeito de sentido no design quando duas questões de projeto são desvendadas. $A$ primeira é o saber criativo atrelado ao tipo de processualidade em questão; a outra é o agir relacional que se desdobra nas dinâmicas de interação já existentes. As iniciativas criativas deixam lacunas a serem ocupadas por meio de um agir estratégico. A dinâmica relacional existente precisa ser elaborada pelo próprio agir estratégico. Nessa direção, Zurlo (2010) associa esse agir estratégico a uma dinâmica dialógica entre os vários atores que fazem parte do processo projetual, designers e não designers.

As reflexões de Meroni (2008) ampliam esse trabalho semântico do design estratégico quando colocado em relação à inovação social, aos processos de codesign e à perspectiva da evolução. A inovação social é geradora 
de processos colaborativos e requer uma articulação ecossistêmica. 0 design estratégico, por sua vez, pode promover uma processualidade capaz de dar conta dessa mobilização dos elementos do sistema. Assim, a criação de um processo de projeto colaborativo é muito bem-vinda para a movimentação da inovação social. Indo ao encontro dessa reflexão, Meroni (2008) compreende que a evolução não é um processo exclusivo de um indivíduo, mas sempre de um indivíduo nas dinâmicas ecossistêmicas de forma que ele deve levar em conta os interesses da comunidade como meio de atingir os individuais. Ou seja, não é algo impositivo, mas articulado e construído entre as pessoas implicadas. Tais grupos são denominados Comunidades Criativas.

São observáveis diferentes manifestações das comunidades criativas ao redor do mundo. Nas cidades do mundo todo, inclusive no Brasil, coletivos criativos formais ou informais (VELASQUES et al., 2016) reúnem-se em espaços que os coletivos porto-alegrenses chamam de Casas Colaborativas. Poderiam ser percebidas como os lares das comunidades criativas da cidade, porque recebem uma diversidade de pessoas que articulam projetos orientados para a inovação sociocultural. As Casas Colaborativas são espaços físicos localizados em diferentes bairros, geralmente materializados em casas ou grandes pavilhões. Possuem diferentes dinâmicas de funcionamento, mas partilham a vontade de promover melhorias orientadas para o bem-estar e a qualidade de vida. As Casas Colaborativas atuam como espaços de coworking e desenvolvem processos de projetos colaborativos. Elas também atuam no sentido de um laboratório de inovação sociocultural. A questão do laboratório confere uma dinâmica específica a esses espaços. Sua forma de agir, tanto por meio de projetos quanto na própria gestão e organização do espaço, ganham proximidade com a experimentação. É da articulação criativa entre diferentes elementos ecossistêmicos que as Casas Colaborativas lidam com sua existência.

Os principais traços comuns às casas são o compartilhamento de um espaço de trabalho, a colaboração no desenvolvimento de projetos coletivos e a orientação para a inovação sociocultural. Por meio deste texto, pretende-se estabelecer uma discussão a respeito do tipo de projetação colaborativa existente nesses espaços denominados como Casas Colaborativas. 


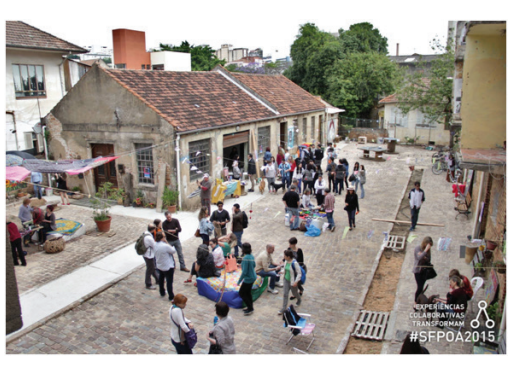

Intervalo do Festival ShareFest 2015, realizado na Casa Colaborativa Vila Flores, em Porto Alegre. O Festival reúne dezenas de pessoas para projetarem em conjunto diferentes temas sugeridos pelos próprios participantes. Fonte: Festival ShareFest.

\section{AS CASAS COLABORATIVAS}

Para abordar o entendimento do que são as Casas Colaborativas é necessária a compreensão do significado de colaboração. Etimologicamente, a palavra "colaboração" encontra sua origem no verbo latim collaborare, composto pela partícula cum, ou seja, "com", "junto", e do verbo laborare, ou seja, "praticar", "trabalhar" (PIANIGIANI, 1907). 0 trabalho pressupõe a construção de algo, a operação ou a produção. Ao encontro dessas contribuições, os autores Tapscott e Williams (2007) propuseram uma reflexão que levantou uma nova associação com a palavra colaboração. Além de chegarem ao entendimento de que também se trata de fazer algo em conjunto, citam a questão da felicidade. Ou seja, a colaboração, no senso comum, é lembrada a partir de pessoas que trabalham juntas e felizes.

Os autores Doorley e Witthoft (2012) ampliam o sentido da colaboração quando discorrem amplamente sobre as múltiplas relações existentes no espaço físico. 0 espaço físico precisa estar condicionado para que ocorra a colaboração. A colaboração pressupõe um processo dinâmico e o espaço deve acompanhar esse movimento. As pessoas precisam ter a oportunidade de mexer no espaço e reconfigurá-lo. Portanto, o mobiliário deve ser de fácil deslocamento e as salas fechadas podem ser evitadas e substituídas por amplos espaços de circulação. Dessa maneira, as pessoas o ocupam da melhor forma.

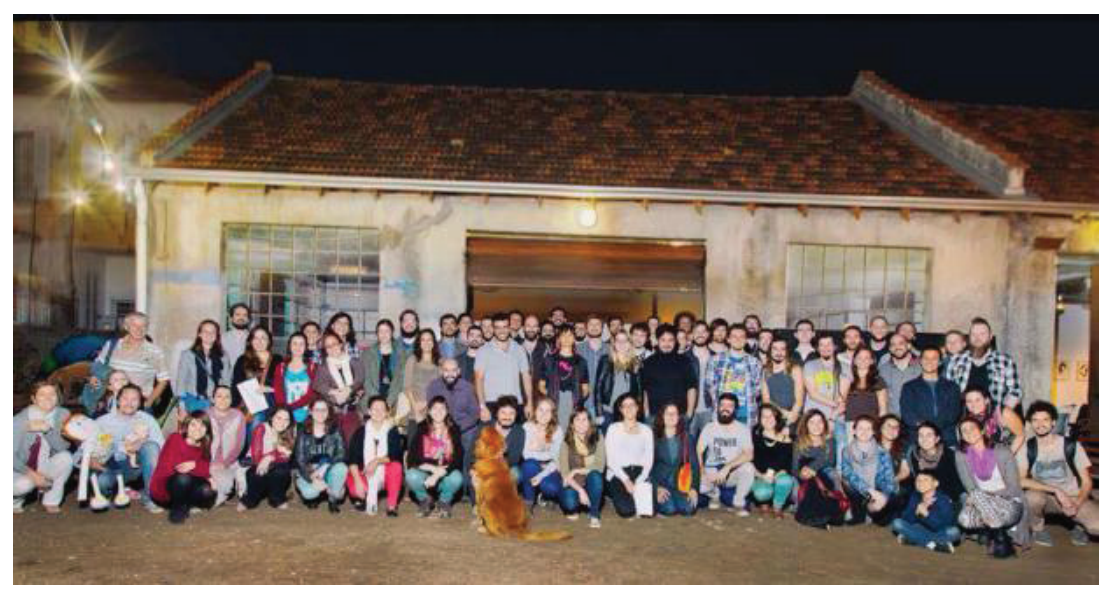

Grande encontro em maio de 2015 entre as Casas Colaborativas de Porto Alegre no Vila Flores. Fonte: Casas Colaborativas. 
O entendimento do conceito de colaboração e essa tônica sobre a dimensão espacial permite uma compreensão inicial das Casas Colaborativas. Para evoluir a compreensão, porém, e possivel conceber as Casas Colaborativas como laboratórios de inovação social, ou seja, de acordo com a etimologia apresentada, como espaços de trabalho sobre novas formas de ação na sociedade e sua prática. Laboratórios são oficinas onde artesãos trabalham com processos manuais, mas também, na Idade Média, eram os espaços dos experimentos alquímicos. Os alquimistas realizavam seus experimentos para novas descobertas por meio da combinações de materiais. Da mesma maneira que as coisas eram submetidas a experimentos, percebe-se que os alquimistas também trabalhavam para outra dimensão de transformação: a de si próprios e de sua consciência. Portanto, a atividade nos laboratórios remete ao plano da transformação pessoal. Os princípios da adaptação e da transformação são úteis na composição de um conceito para as Casas Colaborativas.

Para Sennett (2009), as oficinas funcionavam como as casas dos artífices. É interessante perceber essa associação estabelecida pelo autor no significado atribuído às casas. Os artesãos faziam seus lares dentro das oficinas. Os artífices "pareciam encontrar ali um lar acolhedor, um lugar onde o trabalho e a vida se misturavam frente a frente" (SENNETT, 2009, p. 67). No entanto, havia uma forte orientação para o trabalho. A relação com a sensação de acolhimento nesses espaços não invalida essa predominância de uma atividade focada no trabalho. Ainda para o autor, as oficinas funcionavam orientadas para a interação pessoal direta. Assim, agrega-se ao conceito das Casas Colaborativas a nítida orientação para as interações pessoais e para o trabalho. Plataformas conhecidas pelas nomenclaturas coworking, fablabs ou living labs ajudam a continuar conceituando as Casas Colaborativas como laboratórios de inovação social. Nas três fotos a seguir, identificam-se atividades elaboradas na Casa Colaborativa TransLAB.

Os espaços denominados coworking recebem diversas pessoas para trabalhar no mesmo local. São espaços que alugam postos de trabalho em um ambiente geralmente inspirador. De acordo com o site Coworking Brasil, que reúne muitos espaços dessa natureza, no Brasil, um coworking é um novo modelo de trabalho voltado para profissionais autônomos, freelancers e pequenas empresas que se reúnem em um mesmo espaço para compartilhar experiências e custos. Os fablabs são reconhecidos em

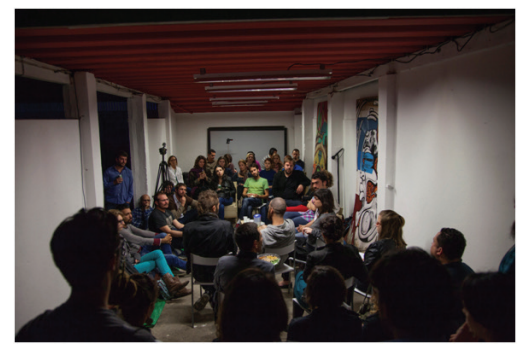

Encontro aberto no Trans $L A B$ entre os representantes das Casas Colaborativas Casa Liberdade, Acervo Independente e Galeria Subterrânea e representantes do governo. Fonte: Trans $L A B$.

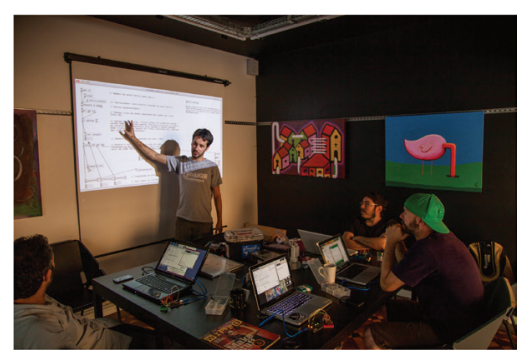

Oficina de Fernando Krum no Trans $L A B$ sobre arduino. Fonte: TransLAB.

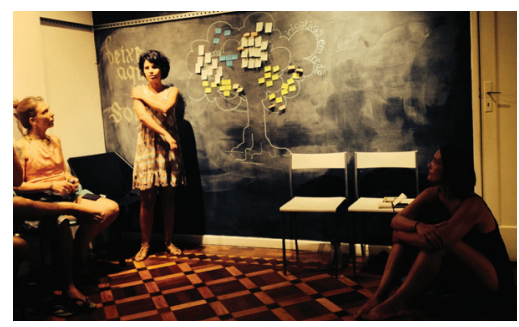

Projetação colaborativa no Trans $L A B$. Fonte: Trans $L A B$. 


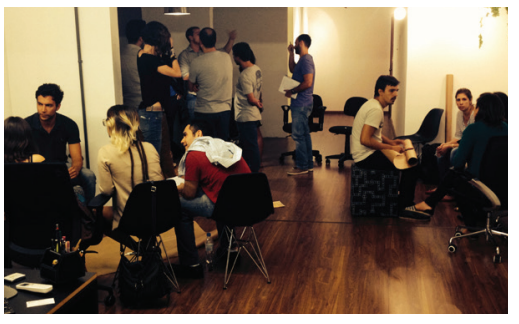

Encontro das Casas Colaborativas. Fonte: Aron Krause.

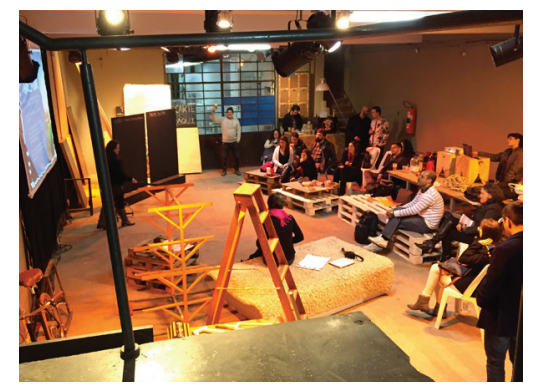

Encontro das Casas Colaborativas no Galpão Makers. Fonte: Aron Krause. salas com equipamentos que convidam à prototipação digital de objetos. Uma consulta ao site Fab Foundation revela que os fablabs são uma organização em rede. Os princípios dos fablabs são claros e conseguem expressar o modo com que se organizam em rede. Um dos princípios que partilham é o conhecimento aberto. Precisa ser um espaço que proporcione a livre expressão das pessoas. A forma como a ENoLL define o conceito de living labs coloca o papel do cidadão no centro da inovação. Além disso, incentiva uma constante pesquisa e inovação orientada para contextos da vida real.

Retomam-se as contribuições dos coworking, fablabs e living labs na conceituação das Casas Colaborativas. A premissa de serem espaços voltados para a colaboração e o compartilhamento posicionam esses locais quanto à sua forma de atuar. 0 compartilhamento de recursos das mais diversas naturezas parece abrir espaço para a colaboração emergir. Dos living labs, recolhe-se, fundamentalmente, sua dinâmica relacional com a comunidade: sua abertura voltada para articulação, cocriação, experiência, aprendizagem e experimentação junto com a sociedade. A partir dos fablabs, é possivel extrair para as Casas Colaborativas o reforço de uma atividade voltada para a experimentação. Fica evidente a organização em rede e a abertura existente. Qualquer um pode integrar a rede, desde que partilhe de princípios em comum. Além disso, há os processos de aprendizagem que derivam de sua processualidade de projetação e uma orientação para um fazer.

\section{O CODESIGN POR MEIO DO PROCESSO DE INTERSUBJETIVAÇÃO}

O codesign sugere uma orientação de fazer com o outro ou de projetar com o outro. Percebe-se uma associação com processos colaborativos e de cocriação dentro de um projeto. 0 codesign refere-se à criatividade dos designers e de pessoas que não estão treinadas em design, trabalhando juntas no desenvolvimento de processos de design (SANDERS; STAPPERS, 2008). Essas pessoas podem assumir diferentes papéis ao longo do projeto. A relação dialógica identificada no design estratégico e transposta para o codesign habilita a multiplicação dos papéis dentro da prática de projetação.

Assim, essa operação aponta para a necessidade de entender o papel do sujeito, que traz um outro significado para os papéis em codesign. 
É o sujeito que precisa ganhar notoriedade frente aos processos evidenciados. Segundo Deleuze (2010), o sujeito é a instância que segue o lugar vazio e desloca-se com agilidade. Ele ocupa novas possibilidades de lugares pela sua dinâmica relacional, a qual o constitui e expressa uma ação que aciona um movimento intersubjetivo. É pertinente a reflexão a respeito da intersubjetivação, porque não apenas enriquece a discussão, como amplia a percepção dos efeitos do projeto colaborativo no âmbito das Casas Colaborativas.

Tendo como objetivo a inovação social, a abordagem do codesign apresenta-se como uma prática projetual bastante adequada nas Casas Colaborativas. É necessário dar espaço para que uma diversidade de sujeitos articule suas ideias para a construção de soluções. 0 desenvolvimento das questões relacionadas à articulação da criatividade coletiva já vem sendo pesquisado pela comunidade acadêmica por meio do uso do termo design participação. Para Lee (2006), design participativo pode ser considerado o conceito "guarda-chuva" de todas as práticas de design que levam em conta a participação de diferentes pessoas no processo, entre as quais o design inclusivo ou o design centrado no humano.

No decorrer da processualidade do codesign identifica-se a função dos papéis do designer, do usuário e do pesquisador (SANDERS; STAPPERS, 2008), e outros papéis ainda poderiam ser identificados. Em um contexto de projetação bastante dinâmico, esses papéis se misturam e passam a existir em novas configurações. Os autores Kleinsmann e Valkenburg (2008) apontam o papel dos atores como a primeira barreira percebida na execução de processos de codesign - isso no sentido da colaboração que deve existir entre eles para a execução de uma tarefa de design. Ainda para esses autores, fatores como a habilidade dos atores em usarem diferentes formas de se comunicar, o conhecimento aplicável do ator no processo e a sua experiência aplicável influenciam diretamente o significado compartilhado.

A relação dialógica identificada no design estratégico e transposta para o codesign é disparadora no reconhecimento dos papéis dentro da prática de projetação. Os autores Sanders e Stappers (2008) reconhecem e afirmam que nem todas as pessoas podem se tornar designers, embora possam ser criativas o suficiente para compor um processo de projeto.

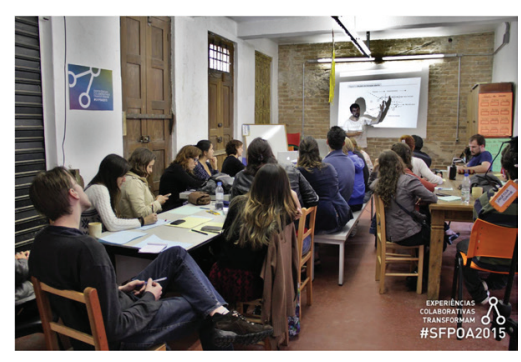

Workshop realizado no Vila Flores para aprendizagem em projetos em rede. Fonte: Festival ShareFest.

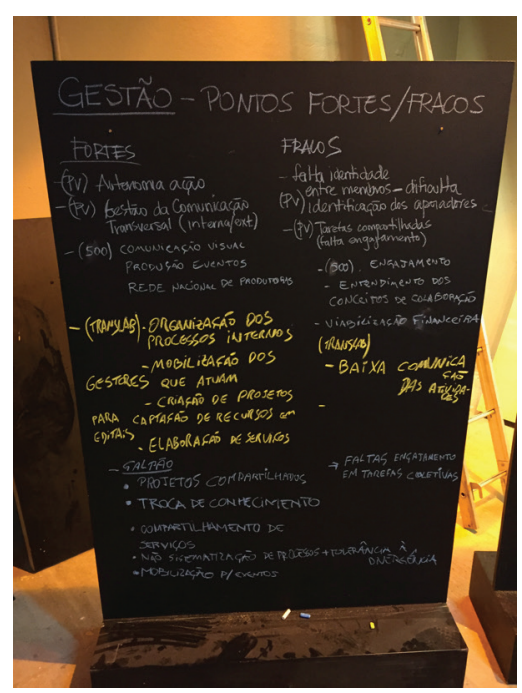

Painel elaborado de forma colaborativa para compartilhar boas práticas de gestão das Casas Colaborativas em encontro no Galpão Makers. Fonte: Aron Krause. 


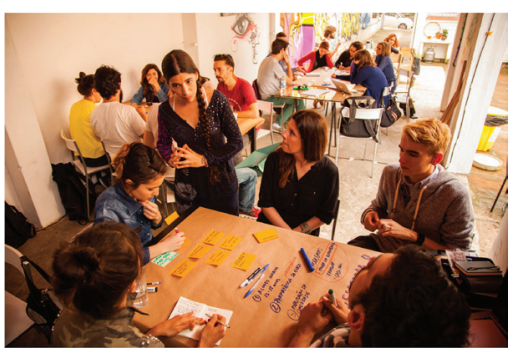

Oficina de codesign facilitada pela pesquisadora espanhola Laia Sanchez no projeto Circuito Montagem no Trans $L A B$. Fonte: Trans $L A B$.

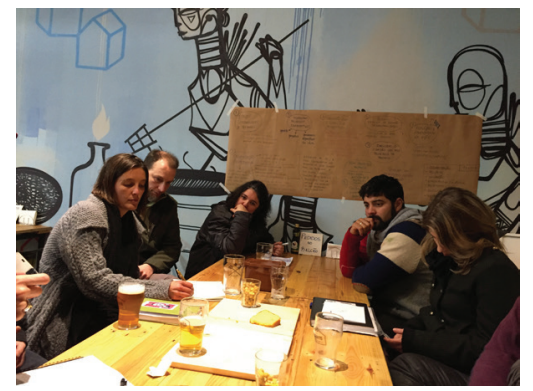

Encontro entre as Casas Colaborativas em cervejaria da cidade de Porto Alegre. Fonte: Aron Krause.
Eles atribuem o nível de paixão, de conhecimento ou de criatividade aos fatores influenciadores para que uma pessoa assuma a função de codesigner. Ainda para os autores, é necessário o uso de ferramentas que promovam a expressão dos usuários. Assim, a elaboração dessas ferramentas ficaria a cargo do designer e do pesquisador. 0 estranhamento no uso das ferramentas por parte dos usuários deve ser absorvido no processo em construção. Com esse movimento, retoma-se a figura do sujeito que tem vontades, desejos, leituras de mundo, bagagem social, cultural, política e econômica diferentes. Ele atribui sentidos diferentes para aquilo que vê. É único na sua condição de existência.

O processo de projeto colaborativo envolve, necessariamente, a produção de subjetividade. Entende-se por subjetividade "o conjunto das condições que torna possivel que instâncias individuais e/ou coletivas estejam em posição de emergir como território existencial" (GUATTARI, 2006, p. 19). O conjunto das condições é algo absolutamente imprevisivel. Quando os sujeitos enfrentam o projeto colaborativo com vistas à inovação social, há um processo de intersubjetivação. Os sujeitos podem entrar nesse processo motivados a encontrarem uma nova relação entre eles, ainda que isso não seja uma percepção concreta. É na processualidade do projeto colaborativo que são desvendadas as qualidades das relações.

Os territórios existenciais mencionados em relação à subjetividade podem ser compreendidos pela maneira como é atribuído sentido àquilo que é feito. Os territórios remetem ao pertencimento, ou seja, aquilo que integra as pessoas por algo em comum. 0 codesign orientado para a inovação social busca a criação de alternativas para novas práticas sociais. 0 sentido que cada sujeito atribui a esse movimento é capaz de produzir relações geradoras de inovação social. Por meio do processo de projeto colaborativo é que as Casas Colaborativas demarcam sua contribuição à inovação social.

Quando um sujeito desterritorializa-se, ou seja, desloca-se para outros territórios existenciais, encontra a possibilidade de construção de outros sentidos. 0 processo de intersubjetivação promove esse tipo de movimento. É por meio da colaboração orientada pela prática do projeto que os sujeitos podem perceber outros territórios existenciais. Esses territórios podem ser outras dimensões simbólicas, anunciadas por aspectos sociais, culturais, ambientais, dentre outros. Essa percepção 
não é apenas contemplativa. Ela é produtora de outros significados. A relação existente entre os sujeitos acompanha esses movimentos de desterritorialização e reterritorialização. Isso justifica uma preparação constante e renovada da subjetividade. Nesse sentido, a maneira como ocorre o projeto colaborativo, o conjunto das condições, influencia diretamente na geração da inovação social. Para Velasques et al. (2016), identifica-se a existência de coletivos criativos informais que também promovem práticas de projeto colaborativo orientadas para um bem comunitário. Para os autores, a informalidade seria um dos motivadores para que se promova o projeto colaborativo. É interessante perceber que, no contexto das Casas Colaborativas, há um movimento de busca pela formalização organizacional. Essa escolha pela institucionalização deve gerar efeitos pertinentes para um acompanhamento neste contexto emergente.

É essencial que sejam organizadas novas solidariedades e uma nova suavidade (GUATTARI, 1990). Isso se reflete na produção de novos modos de subjetividade conduzidos pelos processos de codesign para a criação de inovação social. A produção de conhecimentos e de outras formas de sociabilidade integram os novos agenciamentos produtivos. Identifica-se a oportunidade de reconstrução das relações humanas dentro do contexto da inovação social orientada pelo codesign. Para Guattari (2006), é urgente a ideação de práticas sociais mais voltadas para o futuro, aquelas que devem proporcionar a construção de novos modos de vida. Também é necessário ir ao encontro dos sujeitos interessados nesse processo, no sentido de uma cogestão da produção de subjetividade (GUATTARI, 2006). As atitudes de autoridade e de imposição de ideias devem ser superadas, pois não contribuem para com o processo de agenciamento coletivo.

A compreensão da ideia de experiência encontrada em Sanders (2005) contribui para desenvolver o processo de intersubjetivação inerente ao codesign. A experiência é a composição do que a autora define como as memórias, o momento presente e os sonhos que as pessoas têm. As memórias são todas aquelas experiências que a pessoa teve no passado. Os sonhos são as experiências projetivas ou idealizadas. E o momento presente é o encontro dessas duas representações que compõem a ação da experiência (SANDERS, 2005). É fundamental que as pessoas consigam expressar sua criatividade de diferentes formas. Retoma-se o sentido da prática dialógica por meio de uma ampliação da sua importância e 
significado no projeto colaborativo. A construção de sentido se dá na articulação de diversos elementos que estão em relação.

\subsection{0 projeto colaborativo como dispositivo}

Para Deleuze (1990), um dispositivo exerce uma função e possui um direcionamento. Também não está isolado e permanece em estado de composição. Um dispositivo produz algum saber ou algum tipo de efeito desejável a serviço de um conjunto de interesses partilhados. 0 projeto colaborativo, percebido como um dispositivo, não é neutro em sua totalidade. Ou seja, as Casas Colaborativas tornam-se plataformas de desenvolvimento de inúmeros dispositivos que buscam a inovação social.

Um dispositivo possui linhas que merecem ser compreendidas, para uma ampliação de suas relações com o projeto colaborativo. Na perspectiva deleuziana, encontra-se a metáfora dos dispositivos como um novelo. São muitas linhas entrelaçadas que percorrem caminhos distintos. São geradoras de processos que permanecem instáveis. Há linhas de força que operam como vetores nos desdobramentos processuais. Também há linhas de ruptura ou de fissura que não permitem a estabilidade ou a linearidade do processo. Uma linha de subjetivação é um processo, uma produção de subjetividade num dispositivo (DELEUZE, 1990, p. 157). Existem produções de subjetividade que vão além do reconhecimento e das capacidades de um dispositivo. Se é possível supor que um projeto colaborativo funciona como um dispositivo, entende-se, também, a possibilidade de a sua processualidade deparar-se com o surgimento de tantos novos projetos. Retomam-se as contribuições de Velasques et al. (2016) no sentido de os autores corroborarem a conexão dos coletivos criativos informais junto com outras iniciativas pertencentes ao ecossistema criativo, em função de seus processos difusos.

O projeto colaborativo praticado nas Casas Colaborativas carrega a possibilidade da mudança do regime das soluções para problemas complexos. Ou seja, o entendimento isolado de cada projeto colaborativo realizado nas diferentes Casas Colaborativas não é suficiente para uma compreensão sistêmica de alteração do regime. A originalidade específica de cada projeto dá espaço para a regularidade. Para Deleuze (1990), é a regularidade das enunciações que promove o caminho da alteração 
do regime. É pertinente compreender que a regularidade significa toda linha de curva que passa pelos pontos singulares (DELEUZE, 1990). Ou seja, aquilo que é regular não é linear. Eventualmente, é necessária a sedimentação de processos. No entanto, as linhas de fissura convivem e promovem a iminência da ruptura, anunciando um novo rumo para a construção daquilo que está em curso.

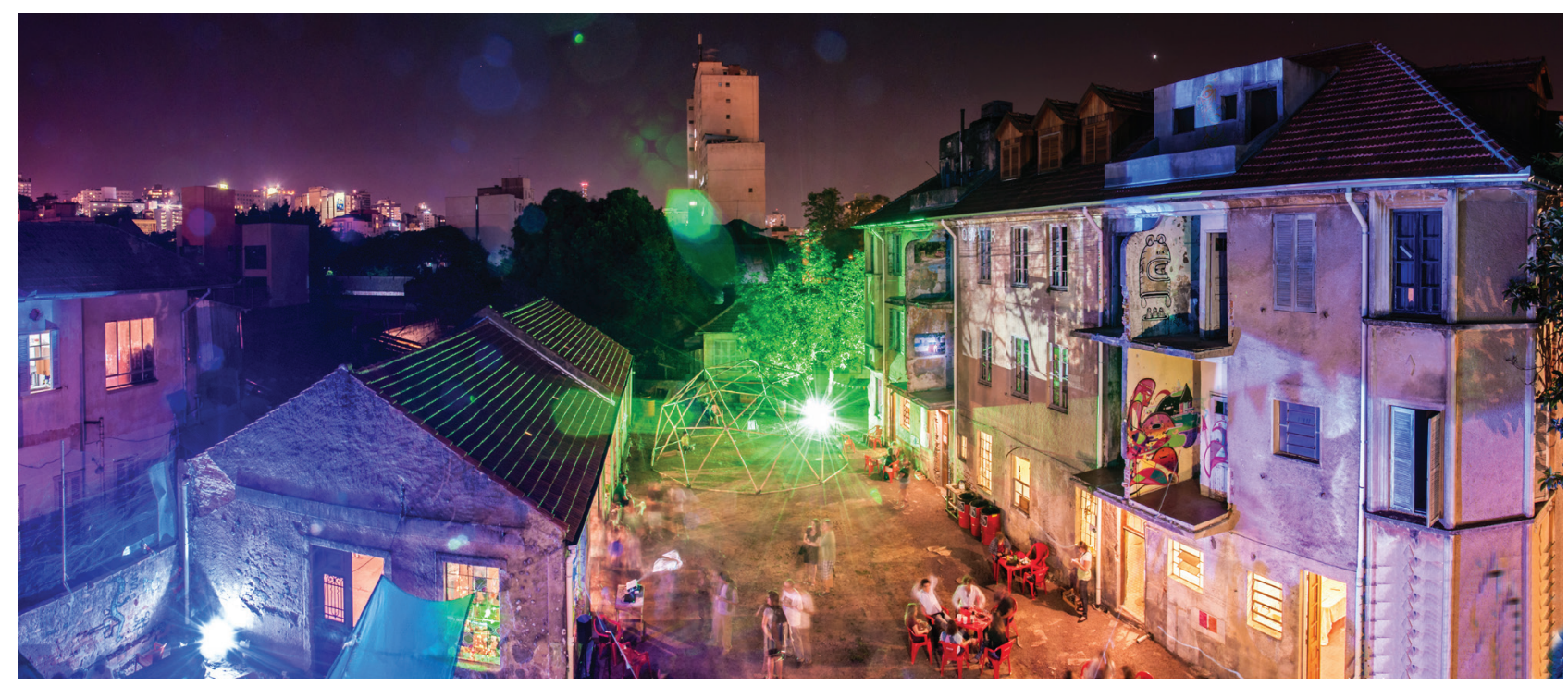

Casa colaborativa Vila Flores, que acolhe dezenas de empreendimentos e iniciativas de inovação social. Crédito da foto: Lauro Rocha.

Assim, é possível evidenciar alguns resultados que permitem reconhecer de forma mais clara aquilo que foi mobilizado pelas Casas Colaborativas. Em função da busca por uma identidade do significado de uma Casa Colaborativa, foi trabalhada coletivamente a construção desse conceito. Em função de uma prática recorrente de encontros mensais entre as Casas Colaborativas, um grupo de pessoas iniciou o desenvolvimento da escrita do conceito de Casa Colaborativa. Esse processo se iniciou por meio de um arquivo compartilhado em Google Drive, no qual foram depositadas as primeiras percepções do significado do conceito. Na medida em que os encontros mensais ocorriam, a conceituação recebia novas elaborações. Em determinado momento, houve a tentativa de inclusão de um verbete na Wikipedia, que no entanto não foi aprovado pelo avaliador da enciclopédia digital. Faltavam mais evidências que tornassem o conceito passivel de ser aceito. Então, uma das pessoas do grupo decidiu aprofundar a conceituação com vistas à formalização do que significa uma Casa Colaborativa. Ainda 


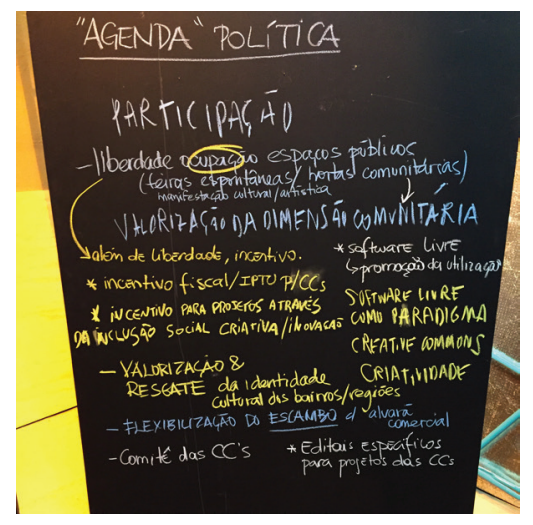

Resultado do painel elaborado de forma colaborativa para construir uma carta que seria direcionada aos candidatos para a Prefeitura de Porto Alegre. Fonte: Aron Krause. que o conceito não esteja publicado e acessível para qualquer interessado, entende-se que esse esforço para seu entendimento representa um resultado capaz de gerar uma identificação pertinente.

Um outro resultado possível de ser evidenciado foi a adesão de algumas Casas Colaborativas ao Movimento Lixo Zero. Também em função dos encontros mensais, nos quais se pratica a projetação colaborativa, os representantes das Casas Colaborativas Vila Flores, Paralelo Vivo e Galpão Makers aderiram ao Lixo Zero. Com uma proposta de promover uma consciência a respeito do lixo que é gerado no espaço, o Lixo Zero promoveu um programa de desenvolvimento para essas Casas Colaborativas. A intenção é que as Casas consigam dimensionar aquilo que é passivel de reciclar e reutilizar e que sejam despertadas para uma responsabilização sobre o volume de resíduos e lixo gerado pelos espaços. A destinação correta dos resíduos sólidos gerados promove um cuidado no impacto ambiental. De forma sistêmica, as Casas Colaborativas engajadas ampliam seu legado social para a cidade.

Em complemento aos resultados alcançados, ainda é possível identificar a projetação de um site das Casas Colaborativas (casascolaborativas. wordpress.com). 0 site foi elaborado para ser um compilado de notícias e informações sobre temas de interesse e atividades desenvolvidas pelas Casas Colaborativas de Porto Alegre. Com uma gestão de conteúdo compartilhada, o espaço digital é aberto para toda e qualquer iniciativa publicar livremente. $O$ desafio é ativar as pessoas vinculadas a cada Casa, para que utilizem o dispositivo digital como mais um canal de divulgação.

\section{ENCAMINHAMENTOS DA REFLEXÃO}

Como todo contexto emergente, o acompanhamento da processualidade decorrente da sua existência é fundamental para o surgimento de novas percepções complementares. As Casas Colaborativas são espaços férteis para a realização de leituras da contribuição aplicada pela área do design. Pelo dinamismo de seus movimentos, comportam múltiplos olhares que colaboram na definição de seus entendimentos.

Uma vez que o projeto colaborativo é compreendido como um dispositivo, posiciona uma visão sistêmica do contexto. A necessidade da percepção 
da interdependência entre os diversos projetos colaborativos é um desafio significativo. As dinâmicas de colaboração para que ocorram as conexões entre as iniciativas requer a elaboração de um processo. Há um aprendizado coletivo para que os processos de projetos colaborativos encontrem os caminhos da complementariedade. Assim, o comprometimento deve estar na manutenção da criação de dispositivos que amplificam os efeitos da inovação social ecossistêmica.

As Casas Colaborativas criam oportunidade para que os sujeitos reconheçam outros territórios existenciais. Elas operam muito mais do que pontos de encontro, porque efetivam o surgimento de um novelo de projetos colaborativos. Observa-se que a diversidade de interesses e desejos mobilizados pelos sujeitos no contexto das Casas sustenta um campo de imanência da inovação social. Assim, a semente de novas Casas deve ser reconhecida para catalisar o ecossistema a que pertence.

\section{REFERÊNCIAS}

COWORKING Brasil. Disponivel em: <https://coworkingbrasil.org/>. Acesso em: 15 maio 2016.

DELEUZE, G. Que és un dispositivo? In: BALIBAR, E. et al. (Orgs.). Michel Foucault, filósofo. Barcelona: Gedisa, 1999, p. 155-163.

A ilha deserta. São Paulo: lluminuras, 2010.

DOORLEY, S.; WITTHOFT, S. Make Space. Canada: John Wiley \& Sons Inc, 2012.

EUROPEAN Network of Living Labs. Disponivel em: <http://www.openlivinglabs.eu/>. Acesso em: 25 maio 2016

FAB Lab Foundation. Disponível em: <www.fablabfoundation.org>. Acesso em: 10 maio 2016. FRANZATO, C. et al. Inovação Cultural e Social: design estratégico e ecossistemas criativos. In: FREIRE, K. (Org.). Design Estratégico para a Inovação Cultural e Social. São Paulo: Kazuá, 2015, p. 157-182.

GUATTARI, F. As três ecologias. Rio de Janeiro: Editions Galilee, 1990. Caososmose: um novo paradigma estético. Rio de Janeiro: Editora 34, 2006.

KLEINSMANN. M.; VALKENBURG, R. Barriers and enablers for creating shared understanding in co- design projects. Design Studies, v. 29, n. 4, p. 369-386, 2008

LEE, Y. Design Participation Tactics: Redefining User Participation in Design. Proceedings of the Design Research Society: Wonderground Conference, Lisbon, IADE, 2006.

MANZINI, E. Design para a inovação social e sustentabilidade: comunidades criativas, organizações colaborativas e novas redes projetuais. Rio de Janeiro: E-papers, 2008

Design when everybody designs. London: The Mit Press, 2015.

MAURI, F. Progettare progettando strategia. Milano: Masson, 1996. 
MERONI, A. Strategic design: where are we now? Reflection around the foundations of a recent discipline. Strategic Design Research Journal, v. 1, n. 1, p. 31-38, 2008. Disponivel em: <http:/l www.unisinos.br/_diversos/revistas/design/pdf/57.pdf>. Acesso em: 10 jan. 2016.

PIANIGIANI, O. Vocabolario etimologico della lingua italiana. Roma: Albrighi \& Segati, 1907. Disponivel em: <http://etimo.it/>. Acesso em: 20 set. 2016.

SANDERS, E. B.-N. Information, Inspiration and Co-creation. Proceedings of the 6th International Conference of the European Academy of Design, Bremen, University Of The Arts, p. 1-14, 2005.

SANDERS, E. B.; STAPPERS, P. J. Co-creation and the new landscapes of design. CoDesign, v. 4, n. 1, p. 5-18, 2008. Disponivel em: <http://www.tandfonline.com/doi/ abs/10.1080/15710880701875068\#.UhEZ3NJWySo>. Acesso em: 20 set. 2016.

SENNETT, R. O artifice. Rio de Janeiro: Record, 2009.

TAPSCOTT, D.; WILLIAMS, D. A. Wikinomics: como a colaboração em massa pode mudar seu negócio. Rio de Janeiro: Nova Fronteira, 2007.

VELASQUES, T.; FRANZATO, C.; DEL GAUDIO, C. Ecossistemas criativos: relações colaborativas e ação projetual nos coletivos criativos informais. IJKEM, International Journal of Knowledge Engineering and Management, v. 4, n. 10, p. 89-106, 2016

ZURLO, F. Design Strategico. In: XXI Secolo. Gli spazi e le arti. Roma: Enciclopedia Treccani, 2010. Disponível em: <http://www.treccani.it/enciclopedia/design-strategico_(XXI-Secolo)/>. Acesso em: 5 out. 2015 